Wright State University

CORE Scholar

Physics Faculty Publications

Physics

$11-1-2004$

\title{
As-Doped p-Type ZnO Produced by an Evaporation/Sputtering Process
}

David C. Look

Wright State University - Main Campus, david.look@wright.edu

G. M. Renlund

R. H. Burgener

J. R. Sizelove

Follow this and additional works at: https://corescholar.libraries.wright.edu/physics

Part of the Physics Commons

\section{Repository Citation}

Look, D. C., Renlund, G. M., Burgener, R. H., \& Sizelove, J. R. (2004). As-Doped p-Type ZnO Produced by an Evaporation/Sputtering Process. Applied Physics Letters, 85 (22), 5269-5271.

https://corescholar.libraries.wright.edu/physics/89

This Article is brought to you for free and open access by the Physics at CORE Scholar. It has been accepted for inclusion in Physics Faculty Publications by an authorized administrator of CORE Scholar. For more information, please contact library-corescholar@wright.edu. 


\title{
As-doped $p$-type ZnO produced by an evaporation/sputtering process
}

\author{
D. C. Look ${ }^{\text {a) }}$ \\ Materials and Manufacturing Directorate, Air Force Research Laboratory, Wright-Patterson Air Force \\ Base, Ohio 45433 and Semiconductor Research Center, Wright State University, Dayton, Ohio 45435
}

G. M. Renlund and R. H. Burgener II

ON International, Inc., 418 West Winchester Street, Salt Lake City, Utah 84107

\author{
J. R. Sizelove \\ Materials and Manufacturing Directorate, Air Force Research Laboratory, \\ Wright-Patterson Air Force Base, Ohio 45433
}

(Received 21 July 2004; accepted 23 September 2004)

\begin{abstract}
Strongly $p$-type $\mathrm{ZnO}$ is produced by the following sequence of steps: (1) evaporation of $\mathrm{Zn}_{3} \mathrm{As}_{2}$ on a fused-quartz substrate at $350{ }^{\circ} \mathrm{C}$; and (2) sputtering of $\mathrm{ZnO}$ with substrate held at $450{ }^{\circ} \mathrm{C}$. The electrical characteristics include: resistivity of $0.4 \Omega \mathrm{cm}$, a mobility of $4 \mathrm{~cm}^{2} / \mathrm{V} \mathrm{s}$, and a hole concentration of about $4 \times 10^{18} \mathrm{~cm}^{-3}$. This resistivity is among the best (lowest) ever reported for $p$-type $\mathrm{ZnO}$. Secondary-ion mass spectroscopic analysis gives an average As concentration about $5 \times 10^{19} \mathrm{~cm}^{-3}$, and a simple one-band fit of the temperature-dependent mobility curve yields an acceptor concentration of about $9 \times 10^{19} \mathrm{~cm}^{-3}$. This is strong evidence that the $p$-type dopant involves As, although it is not clear whether the acceptor is simply $\mathrm{As}_{\mathrm{O}}$ or the recently suggested $\mathrm{As}_{\mathrm{Zn}}-2 \mathrm{~V}_{\mathrm{Zn}}$. (C) 2004 American Institute of Physics. [DOI: 10.1063/1.1825615]
\end{abstract}

Crystalline $\mathrm{ZnO}$ has been studied for more than 50 years, ${ }^{1-3}$ and bulk or epitaxial samples ranging from highly conducting to semi-insulating are now commercially available. ${ }^{4,5}$ However, the conduction properties are not easily controlled, and virtually all "undoped" $\mathrm{ZnO}$ materials are $n$-type, evidently due to background donor impurities such as $\mathrm{Al}$ and $\mathrm{H}$, and native defects such as the $\mathrm{Zn}$ interstitial. ${ }^{1,6-9}$ Indeed, the production of $p$-type $\mathrm{ZnO}$ has proven to be very difficult, and has hindered the development of $\mathrm{ZnO}$-based blue/UV $p-n$ junction light-emitting diodes (LEDs) and laser diodes (LDs). In the last few years, research on $p$-type $\mathrm{ZnO}$ has proceeded at a more rapid pace, ${ }^{10-30}$ in spite of the fact that GaN-based blue LEDs and LDs have already been developed and have found many applications. The reason is that $\mathrm{ZnO}$ has some fundamental advantages over $\mathrm{GaN}$ as a room-temperature emitter, including a more stable exciton, the availability of large-area substrates, the amenability to wet chemical etching, a high radiation resistance, and relatively low materials costs. ${ }^{3}$

A perusal of the periodic table suggests that possible acceptor candidates for $\mathrm{ZnO}$ include Group I elements $\mathrm{Li}$, $\mathrm{Na}, \mathrm{K}, \mathrm{Cu}, \mathrm{Ag}$, and $\mathrm{Au}$, substituting for $\mathrm{Zn}$, and Group V elements N, P, As, and Sb, substituting for O. Although most of these elements have been tested as dopants, only N, P, and As, have produced low-resistivity $(<100 \Omega \mathrm{cm}), p$-type material, to our knowledge. Several groups have found success with $\mathrm{N}$ doping, $10,11,13,14,16,18-20,22-25,28,29$ which is not surprising since the ionic radius of $\mathrm{N}$ is about that of $\mathrm{O}$, so that $\mathrm{N}$ should be quite soluble as $\mathrm{N}_{\mathrm{O}}$. On the other hand, there are only a few reports of $p$-type $\mathrm{ZnO}$ from $\mathrm{P}^{21,27,30}$ or $\mathrm{As}^{12,26}$ doping, and almost no reports involving any of the other possible dopants. In this letter, we discuss an evaporation/ sputtering method of creating As-doped, $p$-type ZnO. This technique has produced $p$-type samples with resistivities as low as $0.1 \Omega \mathrm{cm}$, lower than any others reported so far.

\footnotetext{
${ }^{a)}$ Electronic mail: david.look@wpafb.af.mil
}

Growth was accomplished by first evaporating a layer of $\mathrm{Zn}_{3} \mathrm{As}_{2}$ on a glass substrate at $350{ }^{\circ} \mathrm{C}$, then sputtering $\mathrm{ZnO}$ on top of the $\mathrm{Zn}_{3} \mathrm{As}_{2}$ at $450{ }^{\circ} \mathrm{C}$. Secondary-ion mass spectroscopic (SIMS) data ${ }^{31}$ for layer 12503 are presented in Fig. 1. The As concentration is accurately determined by comparison with an ion-implanted standard, while the $\mathrm{Zn}$ and $\mathrm{O}$ concentrations are simply normalized at the surface to their atomic values of about $4 \times 10^{22} \mathrm{~cm}^{-3}$. An important observation from the $\mathrm{Zn}$ and $\mathrm{O}$ profiles is that they are quite flat over most of the sample, which strongly suggests that the layer is basically $\mathrm{ZnO}$. Further evidence comes from x-ray rocking curves (not shown), which show a dominant (0002) $\mathrm{ZnO}$ reflection.

Note in Fig. 1 that the As signal is very strong in the bottom $0.1 \mu \mathrm{m}$ of the layer, and then quickly reduces to the mid- $10^{19} \mathrm{~cm}^{-3}$ range. We interpret the lower part of the SIMS As profile as possibly representing some remaining $\mathrm{Zn}_{3} \mathrm{As}_{2}$, or some As metal, if all of the $\mathrm{Zn}$ has reacted to form $\mathrm{ZnO}$. Experiments were performed to test the possible electrical activity of this As-dominated layer, especially since

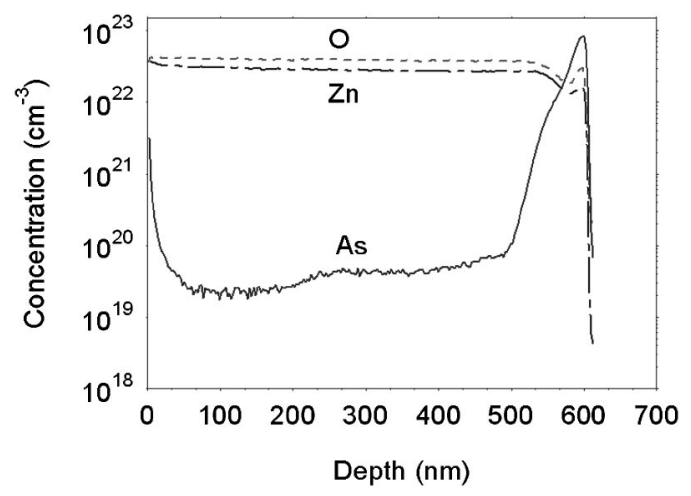

FIG. 1. SIMS measurements of O, Zn, and As in As-doped p-type $\mathrm{ZnO}$. The As concentration is determined from an ion-implanted standard, while the $\mathrm{O}$ and $\mathrm{Zn}$ concentrations are normalized at the surface to roughly their atomic concentrations of $4 \times 10^{22} \mathrm{~cm}^{-3}$ 


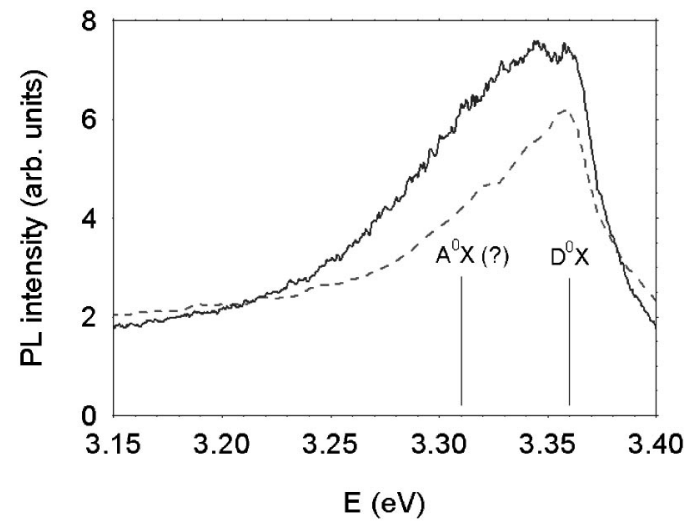

FIG. 2. PL (at $4 \mathrm{~K}$ ) in two As-doped $p$-type $\mathrm{ZnO}$ samples. The dashed line is from a clear region while the solid line represents a darker region, evidently more heavily doped.

both pure $\mathrm{Zn}_{3} \mathrm{As}_{2}$ and As metal are known to be $p$-type, in single-crystalline form. In one such test, the sputtered $\mathrm{ZnO}$ was constrained to only partially overlap the evaporated $\mathrm{Zn}_{3} \mathrm{As}_{2}$, so that three different regions $\left(\mathrm{ZnO}, \mathrm{Zn}_{3} \mathrm{As}_{2}\right.$, and $\mathrm{ZnO} / \mathrm{Zn}_{3} \mathrm{As}_{2}$ ) could be examined separately, after the annealing step was completed. The pure $\mathrm{ZnO}$ region turned out to be $n$-type, as expected, while the $\mathrm{ZnO} / \mathrm{Zn}_{3} \mathrm{As}_{2}$ was $p$-type, and the $\mathrm{Zn}_{3} \mathrm{As}_{2}$, semi-insulating. Thus, it is doubtful that the $\mathrm{Zn}_{3} \mathrm{As}_{2}$ could account for the $p$-type conductivity, in this case. Another possibility is that the layer under the $\mathrm{ZnO}$, after all of the processing, is As metal. However, the resistivity of a metal is known to increase with temperature, and that of our sample decreases. Thus, we believe that the lower As-rich layer, whether $\mathrm{Zn}_{3} \mathrm{As}_{2}$ or metallic As, is not responsible for the $p$-type activity in our material. The rest of the As profile is reasonably flat at the mid- $10^{19} \mathrm{~cm}^{3}$ level, which suggests that the main part of the $\mathrm{ZnO}$ layer is doped with As by a gas-phase reaction, rather than a diffusion process. However, these issues require further study.

As seen in Fig. 2, $4 \mathrm{~K}$ photoluminescence (PL) data show a broad peak in the $3.36 \mathrm{eV}$ region, which is well known as the region of donor-bound exciton $\left(D^{0} X\right)$ lines in $\mathrm{ZnO}$. This is further strong evidence that the layer is basically $\mathrm{ZnO}$, and not some undefined mixture of $\mathrm{Zn}, \mathrm{O}$, and As. The two PL lines in Fig. 2 are from adjacent areas near the edge of the overlapping $\mathrm{ZnO}$ and $\mathrm{Zn}_{3} \mathrm{As}_{2}$ regions, mentioned earlier. The dotted line represents a clear (but still $p$-type) area close to the pure (nonoverlapping) $\mathrm{ZnO}$ region, and the solid line, a darker area just inside the overlapping $\mathrm{ZnO} / \mathrm{Zn}_{3} \mathrm{As}_{2}$ region. The darker area is presumably more heavily doped with As, and indeed has a stronger $p$-type conductivity. Previous PL studies in N-doped and P-doped $p$-type $\mathrm{ZnO}$ have shown that the $D^{0} X$ spectrum moves to lower energies in these materials, enhancing the region of the well-known $3.357 \mathrm{eV}$ feature, and that a new line appears in the $3.31 \mathrm{eV}$ region. ${ }^{19,27,32}$ Although the identities of these lines are still controversial, there is some evidence that each results from acceptor-bound excitons. ${ }^{19,33}$ Whatever its identity, the $3.31 \mathrm{eV}$ line has been found to be associated particularly with $p$-type $\mathrm{ZnO}$, which strengthens the conclusions of the present work.

The temperature-dependent carrier concentration $p$ and mobility $\mu_{p}$ are displayed in Fig. 3. Since the holes are neither fully degenerate nor fully nondegenerate, the curves are not easily amenable to quantitative fitting. However, we have

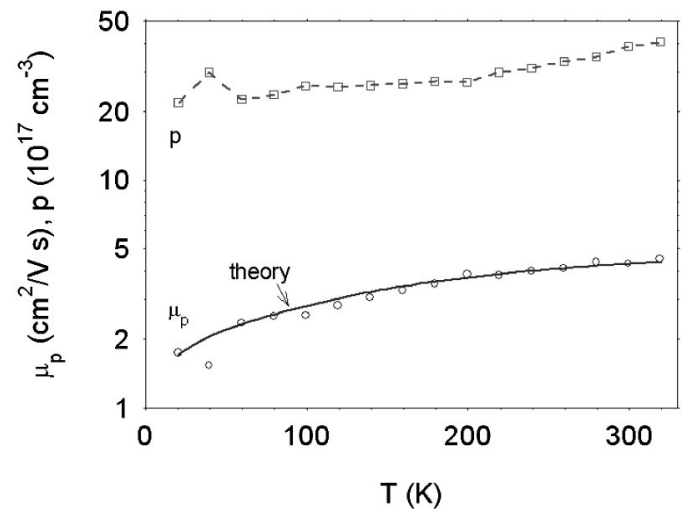

FIG. 3. Hole mobility and concentration in As-doped $p$-type $\mathrm{ZnO}$. The solid curve is a theoretical fit of the mobility assuming a single hole band represented by effective mass $m^{*}=0.64 m_{0}$, and a fitting parameter $N_{\mathrm{D}}=8$ $\times 10^{19} \mathrm{~cm}^{-3}$.

attempted to fit the mobility with a single-band scattering model based on a hole mass of 0.64. (This mass is derived from the assumption that $\mathrm{N}_{\mathrm{O}}$ is a hydrogenic acceptor with a transition energy $E_{\mathrm{A} 0}=133 \mathrm{meV}$ at low acceptor concentrations. The latter value is estimated from: (1) Hall data, ${ }^{34}$ which give $E_{\mathrm{A}} \sim 90 \mathrm{meV}$ at $N_{\mathrm{A}} \sim[\mathrm{N}] \sim 10^{19} \mathrm{~cm}^{-3}$; and (2) the screening formula, $E_{\mathrm{A}}=E_{\mathrm{A} 0}-\beta N_{\mathrm{A}}{ }^{1 / 3}$, with $\beta \sim 2$ $\times 10^{-5} \mathrm{meV} \mathrm{cm}$. The mobility fit is surprisingly good, with a fitting parameter $8 \times 10^{19} \mathrm{~cm}^{-3}$ for the donor concentration $N_{\mathrm{D}}$. The acceptor concentration $N_{\mathrm{A}}$ would then have to be about $9 \times 10^{19} \mathrm{~cm}^{-3}$, since the hole concentration at high temperature is in the $10^{19} \mathrm{~cm}^{-3}$ range. In view of the rather severe approximations involved in the scattering model, it is seen that $N_{\mathrm{A}}$ is quite consistent with the As concentration of about $5 \times 10^{19}$. It is doubtful that the agreement would be this good if the measured layer did not basically consist of As-doped $\mathrm{ZnO}$, as claimed in this work.

Thus, the SIMS, $x$-ray diffraction, PL, and $T$-dependent Hall-effect measurements all indicate that the evaporation/ sputtering method discussed here produces low-resistivity, As-doped, p-type $\mathrm{ZnO}$. However, the microscopic structure of the As-related acceptor is not clear at this point. The simplest structure would be $\mathrm{As}_{\mathrm{O}}$, but density-functional theory suggests that the large ionic radius of As would preclude a high solubility for $\mathrm{As}_{\mathrm{O}}$, and also that the consequent strain relaxation would lead to a deep, not shallow, acceptor. ${ }^{35} \mathrm{An}$ other possibility, recently presented, is that the structure is much more complex, namely, $\mathrm{As}_{\mathrm{Zn}}-2 \mathrm{~V}_{\mathrm{Zn}}$, in which the As substitutes on the $\mathrm{Zn}$ site, forming a donor, but that it then induces two Zn-vacancy acceptors. ${ }^{36}$ The total defect is then acceptor-like, with a $(0 /-)$ transition at $0.15 \mathrm{eV}$ above the valence band. This energy is consistent with our results, but more rigorous confirmation would require analysis of Halleffect measurements in a nondegenerate sample. The $\mathrm{As}_{\mathrm{Zn}}$ $-2 \mathrm{~V}_{\mathrm{Zn}}$ defect also presumably has a significantly lower formation energy than that of $\mathrm{As}_{\mathrm{O}}$, thus predicting a much higher solubility. At this stage, we cannot positively identify either of these structures in our material.

In summary, we have used an evaporation/sputtering method to produce As-doped, p-type ZnO. Structural, opti$\mathrm{cal}$, and electrical properties are all consistent with this conclusion, and the resistivity, an important figure of merit, is among the lowest ever reported for $p$-type $\mathrm{ZnO}$. The dominant acceptor is related to As, but its microscopic structure is not yet established. 
The authors wish to thank T. A. Cooper, J. E. Hoelscher, and W. Rice for technical contributions, and D. C. Reynolds and C. W. Litton for helpful discussions. The work of one of the authors (D.C.L.) was supported under US Air Force Contract F33615-00-C-5402, monitored by J. L. Brown.

${ }^{1}$ D. G. Thomas, J. Phys. Chem. Solids 3, 229 (1957).

${ }^{2}$ P. Wagner and R. Helbig, J. Phys. Chem. Solids 35, 327 (1974).

${ }^{3}$ D. C. Look, Mater. Sci. Eng., B 80, 383 (2001).

${ }^{4}$ ZN Technology, 910 Columbia St., Brea, CA 92821.

${ }^{5}$ Cermet Inc., 1019 Collier Road, Suite C1, Atlanta, GA 30318.

${ }^{6}$ H. Shibata, M. Watanabe, M. Sakai, K. Oka, P. Fons, K. Iwata, A. Yamada, K. Matsubara, K. Sakurai, H. Tampo, K. Nakahara, and S. Niki, Phys. Status Solidi C 1, 872 (2004).

${ }^{7}$ C. G. Van de Walle, Phys. Rev. Lett. 85, 1012 (2000).

${ }^{8}$ D. C. Look, J. W. Hemsky, and J. R. Sizelove, Phys. Rev. Lett. 82, 2552 (1999).

${ }^{9}$ B. K. Meyer, H. Alves, D. M. Hofmann, W. Kriegsies, D. Forster, F. Bertram, J. Christen, A. Hoffmann, M. Straßburg, M. Dworzak, U. Haboeck, and A. V. Rodina, Phys. Status Solidi B 241, 231 (2004).

${ }^{10}$ K. Minegishi, Y. Koiwai, and K. Kikuchi, Jpn. J. Appl. Phys., Part 2 36, L1453 (1997).

${ }^{11}$ M. Joseph, H. Tabata, and T. Kawai, Jpn. J. Appl. Phys., Part 2 38, L1205 (1999).

${ }^{12}$ Y. R. Ryu, S. Zhu, D. C. Look, J. M. Wrobel, H. M. Jeong, and H. W. White, J. Cryst. Growth 216, 330 (2000).

${ }^{13}$ M. Joseph, H. Tabata, H. Saeki, K. Ueda, and T. Kawai, Physica B 302303, 140 (2001).

${ }^{14}$ X-L. Guo, H. Tabata, and T. Kawai, J. Cryst. Growth 223, 135 (2001).

${ }^{15}$ T. V. Butkhuzi, M. M. Sharvashidze, N. M. Gamkrelidze, Kh. V. Gelovani, T. G. Khulordava, N. P. Kekelidze, and E. E. Kekelidze, Semicond. Sci. Technol. 16, 575 (2001).

${ }^{16}$ A. B. M. A. Ashrafi, I. Suemune, H. Kumano, and S. Tanaka, Jpn. J. Appl. Phys., Part 2 41, L1281 (2002).
${ }^{17}$ G. Xiong, J. Wilkinson, B. Mischuck, S. Tuzemen, K. B. Ucer, and R. T. Williams, Appl. Phys. Lett. 80, 1195 (2002).

${ }^{18}$ X-L. Guo, H. Tabata, and T. Kawai, Opt. Mater. (Amsterdam, Neth.) 19, 229 (2002).

${ }^{19}$ D. C. Look, D. C. Reynolds, C. W. Litton, R. L. Jones, D. B. Eason, and G. Cantwell, Appl. Phys. Lett. 81, 1830 (2002).

${ }^{20}$ X. Li, Y. Yan, T. A. Gessert, C. L. Perkins, D. Young, C. DeHart, M. Young, and T. J. Coutts, J. Vac. Sci. Technol. A 21, 1342 (2003).

${ }^{21}$ K. H. Bang, D-K. Hwang, M-C. Park, Y-D. Ko, I. Yun, and J-M. Myoung, Appl. Surf. Sci. 210, 177 (2003).

${ }^{22}$ B. S. Li, Y. C. Liu, Z. Z. Zhi, D. Z. Shen, Y. M. Lu, J. Y. Zhang, X. W. Fan, R. X. Mu, and D. O. Henderson, J. Mater. Res. 18, 8 (2003).

${ }^{23}$ A. V. Singh, R. M. Mehra, A. Wakahara, and A. Yoshida, J. Appl. Phys. 93, 396 (2003).

${ }^{24}$ J. Huang, Z. Ye, H. Chen, B. Zhao, and L. Wang, J. Mater. Sci. Lett. 22, 249 (2003).

${ }^{25}$ X. Li, Y. Yan, T. A. Gessert, C. DeHart, C. L. Perkins, D. Young, and T. J. Coutts, Electrochem. Solid-State Lett. 6, C56 (2003).

${ }^{26}$ Y. R. Ryu, T. S. Lee, and H. W. White, Appl. Phys. Lett. 83, 87 (2003).

${ }^{27}$ K-K. Kim, H-S. Kim, D-K. Hwang, J-H. Lim, and S-J. Park, Appl. Phys. Lett. 83, 63 (2003).

${ }^{28}$ J. Lu, Y. Zhang, Z. Ye, L. Wang, B. Zhao, and J. Huang, Mater. Lett. 57, 3311 (2003).

${ }^{29}$ J. Wang, G. Du, B. Zhao, X. Yang, Y. Zhang, Y. Ma, D. Liu, Y. Chang, H. Wang, H. Yang, and S. Yang, J. Cryst. Growth 255, 293 (2003).

${ }^{30}$ Y. W. Heo, Y. W. Kwon, Y. Li, S. J. Pearton, and D. P. Norton, Appl. Phys. Lett. 84, 3474 (2004).

${ }^{31}$ Evans East, 104 Windsor Center, Suite 101, East Windsor, NJ 08520.

${ }^{32}$ D. C. Look and B. Claflin, Phys. Status Solidi B 241, 624 (2004).

${ }^{33}$ J. Gutowski, N. Presser, and I. Broser, Phys. Rev. B 38, 9746 (1988).

${ }^{34}$ D. C. Look, B. Claflin, Ya. I. Alivov, and S. J. Park, Phys. Status Solidi A 201, 2203 (2004).

${ }^{35}$ C. H. Park, S. B. Zhang, and S. H. Wei, Phys. Rev. B 66, 073202 (2002).

${ }^{36}$ S. Limpijumnong, S. B. Zhang, S. H. Wei, and C. H. Park, Phys. Rev. Lett. 92, 155504 (2004). 